\title{
BUDAYA SUNDA PADA NOVEL PEREMPUAN BERNAMA ARJUNA KARYA REMY SYLADO: SUATU KAJIAN ANTROPOLOGI SASTRA
}

\section{Chintya Bayu Lestari, Zuriyati, Nuruddin}

Pendidikan Bahasa Indonesia, Pascasarjana Universitas Negeri Jakarta, Jalan Raya Rawamangun Muka Jakarta Timur, Indonesia

*Corresponding author: chintyabayulestari_pb16s2@mahasiswa.unj.ac.id

\section{INFORMASI ARTIKEL}

Sejarah Artikel

Diterima: 21/5/2019

Direvisi: 25/11/2019

Diterima: 26/11/2019

Tersedia Daring: 28/11/2019

Kata Kunci

Novel

Antropologi Sastra

Budaya Sunda

\section{ABSTRAK}

Penelitian ini bertujuan untuk mengungkapkan budaya Sunda pada novel Perempuan Bernama Arjuna karya Remy Sylado. Jenis penelitian ini ialah penelitian kualitatif dengan menggunakan metode analisis isi. Sumber data penelitian ini yakni novel Perempuan Bernama Arjuna karya Remy Sylado. Adapun data penelitian ini berupa kutipan kata, kalimat, wacana, atau paragraf yang menunjukan unsur budaya Sunda. Model analisis data menggunakan analisis data Philip Mayring. Hasil penelitian menunjukan bahwa bentuk budaya Sunda pada novel Perempuan Bernama Arjuna karya Remy Sylado dikemas melalui unsur-unsur kebudayaan. Unsur budaya tersebut mencakup (1) sistem pengetahuan sejarah dan kesenian Sunda. (2) Seni tembang. (3) Seni musik. (4) Organisasi sosial berkenaan dengan perkawinan adat Sunda. (5) Bahasa yang diungkapkan mengenai bahasa tulisan.

\section{ABSTRACT}

Keywords

Novel

Literary Anthropology

Sundanese Culture
This article describes the Sundanese culture in literary works in terms of the anthropological approach to literature. The purpose of this research is to reveal about Sundanese culture in the novel Perempuan Bernama Arjuna by Remy Sylado. This type of research is qualitative research using content analysis methods. The data source of this research is the novel Perempuan Bernama Arjuna by Remy Sylado. The data of this study are in the form of words, sentences, discourse, or paragraphs that indicate elements of Sundanese culture. The data analysis model uses Philip Mayrin's data analysis. The results of this study indicate that Sundanese cultural forms in the novel Perempuan Bernama Arjuna by Remy Sylado are packaged through cultural elements. These cultural elements include (1) Sundanese historical and artistic knowledge system. This knowledge system is described by the author through the characters in the novel. Historical knowledge system deals with the history of the regencies of Tasikmalaya, Sunda Kalapa, and the beginnings of Sunda and the knowledge of angklung. (2) The art of songs including Kinanti, Sinom, and Asmarandana; these three songs contain a story about life. (3) The art of music includes flute and harp. Both instruments are Sundanese traditional musical instruments. (4) Social organizations with regards to Sundanese marriages, in which there are several steps in carrying out adat Sundanese marriages. (5) Expressed language regarding the written language.

Copyright@2019, Chintya Bayu Lestari, Zuriyati, Nuruddin This is an open access article under the CC-BY-3.0 license

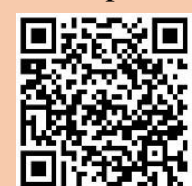

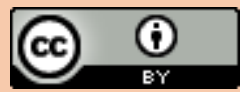




\section{PENDAHULUAN}

Berdasarkan pernyataan Ganjar Kurnia, kesadaran masyarakat Sunda untuk sadar menjaga budayanya sangat kurang. Hal ini dibuktikan dengan sekitar 500 jenis kesenian Sunda hampir punah karena tidak ada regenerasi pemainnya, ciri sikap sejati dari manusia Sunda pun sudah sulit ditemui dalam sikap keseharian masyarakat Sunda zaman kiwari (Maulana, 2013). Hal-hal berikut ini juga dapat menyebabkan pudarnya budaya Sunda yaitu modernisasi, kemajuan teknologi, dan media massa (Choerunisa \& Dahliyana, 2017; Fitriyani, Suryadi, \& Syam, 2015).

Budaya Sunda merupakan salah satu kebudayaan di Indonesia yang terletak di tatar priangan dan mendiami sebagian besar wilayah Jawa Barat serta hidup, tumbuh, dan berkembang di masyarakat Sunda (Fitriyani et al., 2015). Budaya Sunda terwujud dalam bentuk fisik maupun nonfisik yang dapat dinikmati oleh penikmatnya (Susanti \& Koswara, 2017). Kehadiran tema budaya Sunda dalam karya sastra dapat memberikan dokumentasi terhadap rekaman keadaan budaya Sunda.

Pemahaman budaya Sunda dapat diperoleh melalui karya sastra. Karya sastra sebagai media unsur budaya yang dapat memengaruhi masyarakat karena karya sastra diciptakan untuk dipahami, dinikmati, dan dimanfaatkan oleh pembaca (Annisa \& Indiatmoko, 2017). Di sisi lain, karya sastra dianggap sebagai cerminan pengarang pada zamannya untuk menggambarkan keadaan budaya pada waktu itu. Sastra dan budaya tidak dapat dipisahkan karena keduanya memiliki keterkaitan satu sama lain. Sastra mencerminkan keadaan masyarakat suatu wilayah dengan segala aspek yang menyertainya baik aspek sosial, budaya, maupun politik (Wanti, 2014). Seperti pada novel Perempuan Bernama Arjuna karya Remy Sylado yang mengungkapkan secara detail tentang kebudayaan Sunda dari sisi unsur budaya. Novel Perempuan Bernama Arjuna karya Remy Sylado mewakili keadaan budaya Sunda, keadaan tersebut terwujud dalam unsur kebudayaan. Novel tersebut menceritakan tentang perjalanan suami-istri yaitu Arjuna dan Jean-Claude van Damme untuk menggali kebudayaan Sunda meliputi kesenian, bahasa, sistem pengetahuan, dan sebagainya. Ketertarikan terhadap tema novel Perempuan Bernama Arjuna karya Remy Sylado menyebabkan peneliti memilih novel ini untuk digunakan sebagai objek kajian penelitian.

Koentjaraningrat (2015) mengemukakan bahwa terdapat tujuh unsur kebudayaan yakni bahasa, sistem pengetahuan, organisasi sosial, sistem peralatan hidup dan teknologi, sistem mata pencaharian hidup, sistem religi, dan kesenian. Selain itu, unsur kebudayaan terbagi menjadi empat bagian yaitu sistem norma, organisasi ekonomi, alat-alat dan lembaga pendidikan, dan organisasi kekuatan (Setiadi, Kama, \& Effendi, 2008). Begitu juga dengan Mulyana (2012) memasukan lima unsur yang ditemukan dalam setiap budaya: sejarah, agama, nilai-nilai, organisasi sosial, dan bahasa.

Sastra, budaya, dan antropologi saling berkaitan satu dengan yang lainnya. Pemikiran tersebut diungkapkan oleh Endraswara (2013) bahwa karya sastra adalah rekaman peristiwa kebudayaan, dan sebagai rekaman budaya, sastra layak dipahami melalui antropologi sastra sehingga antropologi sastra akan memburu makna sebuah ekspresi budaya dalam sastra. Sehubungan dengan hal tersebut bahwa karya sastra itu menggambarkan keragamanan budaya, untuk menggali keragaman budaya itulah diciptakan suatu pendekatan yakni antropologi sastra. Antropologi sastra adalah analisis dan pemahaman terhadap karya sastra dalam kaitannya dengan kebudayaan (Ratna, 2011).

Penelitian budaya Sunda sudah pernah dilakukan oleh Indrawardana (2012) berjudul Kearifan Lokal Adat Masyarakat Sunda dalam Hubungan dengan Lingkungan Alam penelitian tersebut menjelaskan bahwa kearifan lokal pada masyarakat Sunda Kanekes diutamakan dari pengalaman masyarakat Sunda lama akrab dengan lingkungannya dalam budaya peladangan. Selain itu, terkandung nilai budaya yang adaptif dengan alam sekitar dan tertata secara ajeg 
dalam tatanan adat istiadat masyarakat. Berikutnya, penelitian budaya Sunda dengan judul Menyatukan Perbedaan melalui Seni Budaya Sunda yang dilakukan oleh (Susanti \& Koswara, 2017). Hasil penelitian tersebut menunjukan bahwa seni budaya Sunda sebagai media pembaruan antara etnis Tionghoa dan suku Sunda dalam menerapkan nilai-nilai kesundaan pada kehidupan sehari-hari. Selanjutnya, penelitian budaya Sunda dengan judul Pengaruh Nilai Budaya Sunda dalam Upaya Peningkatan Kesejahteraan Psikologis Korban Bencana Tanah Longsor yang dilakukan oleh (Kadiyono \& Harding, 2017). Hasil dari penelitian tersebut ialah nilai budaya Sunda yang dianut oleh penduduk Cianjur dapat meningkatkan kesejahteraan psikologis. Perbedaan penelitian ini dengan tiga penelitian terdahulu di atas, dalam penelitian ini lebih memfokuskan pada unsur kebudayaan yang terkandung dalam novel Perempuan Bernama Arjuna karya Remy Sylado.

Berdasarkan pemaparan di atas, maka rumusan masalah ini adalah bagaimana bentuk budaya Sunda pada novel Perempuan Bernama Arjuna karya Remy Sylado. Sementara tujuan dari artikel ini adalah mengungkapkan secara mendalam bentuk budaya Sunda pada novel Perempuan Bernama Arjuna karya Remy Sylado. Kebaruan dari artikel ini ada terletak pada topik penelitian mengenai budaya Sunda di dalam karya sastra.

\section{METODE}

Jenis penelitian ini yaitu penelitian kualitatif dengan menggunakan metode analisis isi. Metode analisis isi (content analysis) ialah penelitian yang menganalisis dokumen untuk diketahui isi dan makna yang terkandung dalam dokumen tersebut (Pradopo, 2017). Dokumen yang dimaksud dalam penelitian ini yaitu novel. Adapun pendekatan penelitian yang digunakan ialah pendekatan antropologi sastra.

Penelitian ini menggunakan sumber data primer dan sekunder. Sumber data primer yaitu novel Perempuan Bernama Arjuna karya Remy Sylado cetakan pertama tahun 2017 diterbitkan oleh Nuansa Cendikia. Sedangkan, sumber data sekunder yaitu artikel, prosiding, buku, dan website. Data sekunder berfungsi untuk memperoleh teori yang akan digunakan dalam temuan data penelitian. Data penelitian ini adalah kutipan kata, kalimat, paragraf, atau wacana yang menunjukan adanya unsur budaya Sunda pada novel Perempuan Bernama Arjuna karya Remy Sylado.

Prosedur pengumpulan data yang dilakukan oleh peneliti sebagai berikut (a) membaca dan memahami isi novel Perempuan Bernama Arjuna secara mendalam, (b) menentukan unsur budaya Sunda, (c) mencatat kutipan kata, kalimat, paragraf, atau wacana yang mengandung unsur budaya Sunda, dan (d) menggunakan studi kepustakaan untuk mendapatkan data sekunder sebagai pelengkap data mengenai unsur budaya Sunda. Analisis data yang digunakan dalam penelitian ini adalah analisis data model analisis isi kualitatif Philipp Mayring. Menurut Emzir (2016) analisis isi kualitatif disajikan atas sekumpulan teknik untuk analisis teks. Langkah-langkahnya sebagai berikut (a) membaca isi novel, (b) melakukan proses identifikasi, (c) mengklasifikasi temuan data, (d) melakukan pengkodean untuk merincikan unsur budaya Sunda, (e) menganalisis novel Perempuan Bernama Arjuna karya Remy Sylado ditinjau dari unsur budaya Sunda, (f) menuliskan hasil analisis data yang telah diolah, (g) melakukan pembahasan hasil penelitian, dan (h) menarik kesimpulan.

\section{HASIL DAN PEMBAHASAN}

Pada bagian ini akan memaparkan analisis temuan data penelitian terkait bentuk kebudayaan Sunda yang terdapat dalam novel Perempuan Bernama Arjuna karya Remy Sylado. Bentuk-bentuk budaya ini akan dibedah menggunakan pendekatan antropologi sastra. Bentuk budaya yang terwujud meliputi unsur kebudayaan yang dikemukakan oleh 
Koentjaraningrat. Berikut ini temuan data dan hasil analisis mengenai budaya Sunda dalam novel Perempuan Bernama Arjuna karya Remy Sylado.

\section{Sistem Pengetahuan}

Sistem pengetahuan termasuk dalam suatu kebudayaan (Koentjaraningrat, 2015). Tiaptiap pengetahuan di dalam suatu suku bangsa berbeda-beda sehingga memiliki cabang pengetahuan. Sistem pengetahuan merupakan sebuah hasil budaya meskipun berwujud abstrak tetapi dapat dipelajari dan memiliki manfaat bagi yang mempelajarinya. Temuan data sistem pengetahuan yang ditemukan dalam novel ini mencakup pengetahuan sejarah dan kesenian. Sistem pengetahuan sejarah terdiri dari pengetahuan sejarah Sunda Kalapa, Sunda, dan Tasikmalaya sedangkan, sistem pengetahuan kesenian meliputi pengetahuan angklung. Sistem pengetahuan sejarah Sunda Kalapa ini diungkapkan oleh tokoh Takeshita dan Arjuna ketika Arjuna dan suami berkunjung ke rumah Takeshita. Berikut ini temuan data sistem pengetahuan.

\section{Pengetahuan Sejarah Sunda Kalapa}

Sunda kalapa merupakan pelabuhan tempat para pedagang berlabuh. Berdasarkan hasil wawancara pada tanggal 18 Februari 2019 dengan budayawan sekaligus ahli bahasa yaitu Yayat Sudaryat mengatakan bahwa Sunda kalapa berganti nama menjadi Jakarta, dahulunya merupakan pesisir kerajaan Pajajaran. Beliau juga mengatakan bahwa wilayah kekuasaan Pajajaran juga melingkupi Banten. Pada waktu itu Banten berada di bawah kekuasaan Pajajaran. Pajajaran merupakan kerajaan Sunda di Bogor. Perhatikan temuan data di bawah ini.

“Bukan 'kelapa', tapi 'kalapa'. Setahu aku, dalam bahasa Sunda lama, yang dulu dipakai untuk nama Jakarta, sebagai pelabuhan utama kerajaan Sunda di Bogor, yaitu Pakuan Pajajaran, adalah kalapa berarti 'bandar' atau 'pelabuhan'. Jadi Sunda Kalapa, maksudnya adalah Bandar atau pelabuhan dari kerajaan Sunda, Pakuan Pajajaran, dengan raja akhir yang sangat dimuliakan dan harum namanya, Prabu Siliwangi" (PBA, 2017:10)

Data tersebut mengungkapkan bahwa dahulu kala Sunda Kalapa sebagai pelabuhan kerajaan Pajajaran. Sampai saat ini Sunda Kalapa masih berfungsi sebagai pelabuhan. Pelabuhan Sunda Kalapa terletak di Penjaringan, Jakarta Utara. Saat ini, fungsi Sunda Kalapa hanya melayani antarpulau di Indonesia. Di sini juga masih terdapat kapal-kapal pinisi yang terbuat dari kayu untuk mengangkut logistik ke berbagai pulau di Indonesia. Pelabuhan ini merupakan pelabuhan tertua di Indonesia dan sudah ada sejak abad ke-5. Namun, pada abad ke-12 berpindah tangan menjadi milik kerajaan Sunda. Kegiatan di pelabuhan ini di dominasi oleh kegiatan perdagangan.

Pelabuhan ini digunakan sejak zaman Tarumanegara dan diperkirakan sudah berada sejak abad ke-5 saat itu dinamai Sundapura dan berganti nama menjadi Sunda Kalapa pada tahun 1970-an. Dewasa ini, pelabuhan Sunda Kalapa direncanakan menjadi kawasan wisata sejarah. Adanya pengetahuan Sunda Kalapa ini untuk mengingatkan kembali bahwa dahulu kala kerajaan Pajajaran yang terletak di daerah Bogor memiliki sebuah pelabuhan yang bernama Sunda Kalapa serta Sunda Kalapa ini sebagai cikal bakal nama kota Jakarta.

\section{Pengetahuan Sejarah Sunda}

Pengetahuan sejarah Sunda yang dibahas dalam novel Perenpuan Bernama Arjuna karya Remy Sylado mengenai wilayah Sunda. Istilah Kepulauan Sunda merupakan istilah pertama yang tercatat pada literature geografi dunia. Ada seorang geologi berkebangsaan Belanda yakni Bemmelen, menggunakan istilah kepulauan Sunda untuk mendefinisikan kepulauan yang 
terbentuk pada akhir zaman Milosen. Sebagaimana pengetahuan sejarah Sunda terdapat dalam temuan data berikut ini.

Tunggu dulu," kata Takeshita dengan serius, tapi diucapkan seperti canda. "Ya, boleh saja pulau ini bernama Pulau Jawa. Tapi jangan lupa, dalam peta lama, pulaupulau besar Nusantara antara Sumatra, Jawa, termasuk Kalimantan, dulunya disebut Kepulauan Sunda Besar, atau bahasa Belandanya Groot Soenda Eiland. Lantas, pulau-pulau kecil di seberang timur Banyuwangi, dimulai dari Pulau Bali sampai Pulau Timor, zaman dulu disebut Kepulauan Sunda Kecil, atau bahasa Belandanya Klein Soenda Eiland. Dengan begitu artinya, Sunda tidak terkalahkan kebudayaannya. Ha-ha-ha" (PBA, 2017:32)

Temuan data tersebut bahwa dahulu kala Sunda sebagai sebuah pulau besar di Nusantara. Di sisi lain, Sunda merupakan nama sebuah suku. Sunda sebagai wilayah yang kaya akan kebudayaannya serta keramahtamahan akan masyarakatnya. Sunda di dalam peta lama Nusantara merupakan sebuah pulau. Artikel berjudul Kenapa Benua Tenggelam itu Bernama Sundaland? dikutip dari detik.com yang terbit pada Rabu, 27 Oktober 2010, Sundaland menurut Oppenheimer sebutan untuk benua yang sebagian tenggelam di Asia Tenggara. Sundaland sebagai istilah geologis dan sudah lama digunakan. Sundaland merupakan nama pemberian pembuat peta dari protugis. Disebut Sundaland karena pada waktu itu di Jawa sudah ada kerajaan Sunda. Sundaland terdiri dari pulau Sunda Besar, Sunda Kecil, dan Laut Sunda.

\section{Pengetahuan Sejarah Tasikmalaya}

Tasikmalaya adalah kabupaten di Jawa Barat. Dahulunya pemerintahan Tasikmalaya ini dipimpin oleh kerajaan. Bahkan dahulu kala, pemilihan bupati di daerah ini diangkat oleh kerajaan. Setelah masuknya Islam, kerajaan di daerah Tasikmalaya ini melepaskan diri dari Pajajaran (hasil wawancara dengan Yayat Sudaryat). Temuan data pengetahuan sejarah Tasikmalaya sebagai berikut.

Tapi, sebelum itu, tunggu sebentar. Saya punya sedikit catatan tentang Tasikmalaya dan Ciamis. Pertama, Tasikmalaya. Saya tahu, dan mestinya Anda juga tahu, bahwa kata tasik dalam bahasa Indonesia - begini menurut Kamus Besar Bahasa Indonesia - adalah 'kawasan air yang luas yang dikelilingi oleh daratan'. Dan Malaya, saya tahu, dan mestinya Anda tahu juga, bahwa ini adalah nama lama semenjung di tenggara Asia yang sekarang menjadi Negara Malaysia. ( $P B A$, 2017:194)

Ternyata, kata dia, sebelum bernama Tasikmalaya, kota yang sekarang menjadi pusat pemerintahan kabupaten ini, dulunya memang bernama Sukapura. Baru pada 1913, di zaman pemerintahan Bupati Wiratanuningrat, maka Sukapura diganti menjadi Tasikmalaya. Kendati begitu hari jadinya ditetapkan oleh DPRD Kabupaten Tasikmalaya adalah 21 Agustus 1111. Jadi usianya menjelang sepuluh abad. (PBA, 2017:195-196)

Pengetahuan ini dijelaskan secara rinci oleh pengarang melalui tokoh Arjuna mulai dari penamaan dan hari jadi wilayah Tasikmalaya. Tasikmalaya memiliki peristiwa lokal yang secara langsung maupun tidak langsung yang mempengaruhi roda jalannya sejarah bangsa Indonesia. Peristiwa tersebut ada yang bernuansa sosial, budaya, dan sebagainya (Hardiana, 2017). Walaupun Tasikmalaya sebuah kota/kabupaten yang luasnya tidak terlalu besar tetapi kota/kabupaten ini menyimpan sumber pengetahuan sejarah. 


\section{Pengetahuan Kesenian Angklung}

Angklung merupakan alat musik tradisional Sunda. alat musik ini terbuat dari bambu, tersusun secara longgar dalam sebuah kerangka bambu. Pengetahuan ini mengungkapkan bahwa di wilayah Sunda terdapat berbagai macam jenis angklung. Adapun jenis angklung yang diungkapkan dalam pengetahuan ini berkenaan dengan angklung tradisional. Lihatlah temuan data di bawah ini.

"Sekarang, setelah masyarakatnya sudah memeluk teguh agama Islam, permainan angklung badeng dimanfaatkan juga untuk piranti dakwah. Entah kebetulan atau memang berkaitan dengan syiar Islam, bahwa para wali yang membawa Islam di Jawa, dan meluas ke sini, terdiri dari Sembilan mubalig, maka angklung badeng pun terdiri dari Sembilan buah, masing-masing dua buah angklung roel, satu buah angklung kecer, empat buah angklung indung \& bapa, dan dua buah angklung anakan. Angklung-angklung itu dilengkapi juga dengan jenis membranofon berupa dua buah dogdog, dua buah trebang, dan satu buah kecrek" (PBA, 2017:163)

"Hampir-hampir sama kecuali talanya," kata Yayat Sunarya. "Dan, uniknya, di Kenekes angklung dimainkan oleh delapan orang pria ditambah lagi tiga orang pria lain yang menabuh sejenis tambur. Mereka bermain sambil berdiri dan berputar, lantas ada juga beberapa orang secara improvisasi bergerak-gerak seakan menari, lazimnya mereka menyambut itu galage." (PBA, 2017:164)

Pengetahuan mengenai angklung memberitahukan kepada pembaca bahwa angklung memiliki berbagai macam jenis dan fungsinya. Konon, alat musik ini sudah ada sejak zaman kerajaan Sunda. Jenis-jenis angklung mempunyai perbedaan dari segi hiasan dan banyak tabung (Hermawan, 2013).

Data tersebut memaparkan bahwa fungsi utama permainan angklung di tatar Sunda digunakan pada saat upacara menanam padi sebagai bentuk penghormatan kepada Dewi Padi yaitu Sri Pohaci. Setelah masuknya Islam fungsi angklung memiliki perubahan yaitu sebagai media dakwah yang dibawa oleh para wali songo dalam menyebarkan agama Islam.

Pengetahuan jenis angklung yang dijelaskan dalam novel Perempuan Bernama Arjuna di antaranya angklung badeng dan kanekes. Angklung badeng adalah jenis kesenian yang menekankan segi musikal dengan angklung sebagai alat musik utama. Angklung badeng terdapat di Kabupaten Garut. Zaman dahulu, angklung ini fungsinya untuk kepentingan dakwah Islam sedangkan, angklung kanekes adalah angklung berasal dari Banten. Kanekes ini merupakan nama dari sebuah desa di Kecamatan Ciboleger, Kabupaten Lebak. Angklung di daerah Kanekes digunakan terutama untuk ritus padi, bukan semata-mata untuk hiburan.

\section{Seni Tembang}

Seni berarti penggunaan imajinasi dan kreatifitas manusia dalam menerangkan, memahami, dan menikmati kehidupan. Kesenian merupakan salah satu cara manusia memandang dunia (Sugeng, 2015). Seni sebagai permainan dengan bentuk yang menghasilkan representasi-transformasi yang sukses secara estetis (Harris, 1995). Kesenian terbagi menjadi seni lukis, seni tembang, seni patung, seni tari, tato, dan urban art (Sugeng, 2015).

Dalam novel Perempuan Bernama Arjuna karya Remy Sylado ditemukan adanya data budaya Sunda berupa seni tembang. Seni tembang sebagai representasi dari kesenian Sunda dan ciri khas Sunda. Seni tembang dalam kesenian Sunda disebut mamaos. Tembang Sunda menurut Wiradiredja (2012) ialah seni suara Sunda dengan menggunakan seperangkat 
instrumen atau alat musik pengiring terdiri dari kacapi, suling, atau rebab. Seni tembang Sunda termasuk dalam seni sunda bersifat klasik. Berikut ini temuan data tembang kinanti.

Setelah kedua instrumen itu dimainkan sebagai bebuka, atau dalam istilah anak-anak band adalah 'intro', maka Takeshita pun menyanyikan tembang Kinanti. Kata-katanya begini:

\author{
Simkuring seja mihatur \\ Reh tadi mahekeun cai \\ Digantian ku nu anyar \\ Menggah pikiran simkuring \\ Reh sejen jeung jalma rea \\ Pas siga Bupati (PBA, 2017:53)
}

Data di atas mengungkapan adanya tembang kinanti. Tembang Sunda ini dinyanyikan oleh Takeshita ketika Arjuna dan suami berkunjung ke rumahnya. Tembang tersebut menceritakan mengenai perbedaan pendapat. Perbedaan pendapat pada masyarakat Sunda wajar saja terjadi tetapi sikap dalam mengemukakan pendapat harus disertai dengan tata krama. Masyarakat Sunda terkenal dengan sopan santunnya atau someah walaupun berbeda pendapat, hendaknya tata krama dalam mengemukakan pendapat tetap dijaga ketika musyawarah.

Tembang Sunda berikutnya ialah tembang sinom, temuan datanya terdapat pada kutipan di bawah ini. Setelah Takeshita berkata begitu, Mang Engkus membunyikan kacapinya, memainkan bebuka, sambil berkata kepada Taksehita, "Neng, ieu ayena sinomnya?"...

Dan dia pun menyanyi, begini:

Sanggeusing layar ti dinya

Laut awon henteu lami

Kapal muntir sakedap

Teu lila bral layar deui

Manggih pulo laleutik

$\mathrm{Nu}$ keurkeun barang di laut

Nu laku kana uang

Tuluy dibelikeun deui

Kana barang nu kira aya batina

(PBA, 2017:54 - 55)

Tembang di atas mengungkapkan adanya tukar-menukar barang. Tukar-menukar barang ini dilakukan setelah berlayar. Kemungkinan masyarakat pada zaman dahulu untuk membeli kebutuhan dapur atau yang lainnya menggunakan tukar menukar barang atau barter. Barter adalah transaksi yang digunakan untuk menukar barang sebelum mengenal uang. Pada zaman dahulu, sebagian masyarakat yang bekerja sebagai nelayan menukarkan hasil tangkapannya dengan uang atau barang yang bisa digunakan untuk memenuhi kebutuhan hidupnya.

Berikutnya tembang Sunda yang ditemukan dalam novel Perempuan Bernama Arjuna karya Remy Sylado adalah tembang asmarandana. Temuan datanya sebagai berikut. Takeshita sendiri memberi senyum kepada kami. Dia memandang Mang Engkus sambil berkata, "Mang, sekarang kita coba mainkan asmarandana" Eep membunyikan suling diiring kecapi oleh Mang Engkus lantas Takeshita pun menembang asmarandana, yaitu puisi berlarik tujuh baris dengan baris pertama terdiri dari delapan sukukata dan baris ketujuh terdiri dari delapan suku kata pula. Begini: 


\section{Raja ngalahir ka patih \\ Kaula geus meunang beja \\ Carita jaman bareto \\ Keur alam nabi Sulaeman \\ Lebetna alus pisan \\ Kula hayang liwat langkung \\ Ayeuna kuma petana \\ (PBA, 2017:56)}

Tembang ini menceritakan seorang raja sedang berbicara kepada patih perihal cerita nabi Sulaeman. Isi cerita nabi Sulaeman dalam tembang tersebut tidak diceritakan secara rinci hanya disebutkan cerita nabi Suleman saja. Akan tetapi, cerita nabi Suleman menceritakan tentang kekuasaan nabi Sulaeman bahwa semua umatnya atau manusia itu tunduk dan patuh serta melaksanakan perintah nabi Suleman. Selain itu, nabi Suleman juga mengerti bahasa binatang. Hubungannya dengan isi tembang di atas kemungkinan raja menginginkan rakyatnya tunduk, taat, dan menuruti perintahnya. Mungkin hal tersebut tidak ditemukan oleh raja pada rakyatnya. Berdasarkan isi tembang di atas, kemungkinan ada keterkaitan dengan kerajaan Sunda bahwa raja kerajaan Sunda menginginkan rakyatnya seperti umatnya nabi Sulaeman yang patuh, taat, dan tunduk.

Masyarakat Sunda gemar sekali menembang maka lahirlah tembang Sunda atau mamaos sebagai bagian dari budaya Sunda. Pada umumnya, tembang Sunda mengandung nasihat, ajaran, atau cerita yang ingin disampaikan.

\section{Seni musik}

Kecapi suling merupakan kesenian yang terdiri dari instrumen kacapi dan suling. Kecapi dan suling adalah salah satu seni budaya yang hidup memiliki kekhasan dan mengandung banyak hal menyangkut budaya daerah. Awalnya alat musik kecapi memiliki fungsi untuk mengiringi upacara siraman bangsawan Cianjur. Seiring dengan berkembangnya zaman, fungsi kecapi memiliki perubahan beralih sebagai media hiburan dan pertunjukan (Arini \& Supriadi, 2011). Berikut ini terdapat temuan data kecapi dan suling dalam novel Perempuan Bernama Arjuna.

Takeshita memperkenalkan kepada kami kedua orang itu, Sang ayah bernama Kusna yang dipanggil Mang Engkus. Dia cekatan memainkan kecapi. Dan sangat anak bernama Sueb yang dipanggil Eep. Dia pun sangat cekatan memainkan suling. $(P B A, 2017: 51)$

Temuan data tersebut menunjukan adanya dua alat musik Sunda yaitu kecapi dan suling. Kedua alat musik ini merupakan alat musik tradisional Sunda. Keduanya terbuat dari bambu. Kecapi memiliki 20 senar. Dalam kehidupan masyarakat Sunda, bambu menjadi bahan utama dalam memenuhi kebutuhan. Bambu dimanfaatkan oleh masyarakat Sunda untuk memenuhi kebutuhan sehari-hari seperti membuat rumah, permainan, dan alat musik. Dengan demikian, kesenian di masyarakat Sunda tumbuh dari kreativitas orang Sunda dalam memanfaatkan alamnya.

\section{Organisasi sosial}

Organisasi sosial merupakan hubungan antara kelompok, status, dan pembagian kerja yang menyusun interaksi orang dalam masyarakat. Organisasi sosial mencakup pranata-pranata 
yang menentukan kedudukan laki-laki dan perempuan dalam masyarakat dengan menyalurkan hubungan pribadi mereka (Ihromi, 2017). Kategori atau pranata ini terbagi menjadi hubungan kekerabatan dan hubungan hasil dari ikatan antara perorangan berdasarkan keinginan pribadi. Dalam novel ini menerangkan adanya organisasi sosial berikut ini temuan datanya.

Kami berdua - saya dan Jean-Claude van Damme sang jantunghati - ditambah satu orang yang menjadi tiga, yaitu Takeshita, terpaksa berhenti dengan senang dijalanan menuju ke Gunung Padang, sebab di desa ujung sebelum berbelok ke kanan yang agak mendaki, ada pesta adat perkawinan khas Sunda yang ramai nian. Kata Takeshita, upacara perkawinan adat Sunda - seperti yang sebelumnya pernah disaksikannya dan dibacanya pula dari buku Pesta Adat Jawa Barat yang ditulis oleh Yulian Ardi Wirawan ST - dimulai melalui neundeun omongan, harfiahnya berarti 'menyimpan ucapan'.

$(P B A, 2017: 79)$

Data di atas mengungkapkan bahwa organisasi sosial yang terdapat dalam novel Perempuan Bernama Arjuna berupa sistem yang menentukan hubungan antara laki-laki dan perempuan melalui perkawinan. Budaya Sunda memiliki sistem perkawinan adat Sunda yang digunakan oleh masyarakatnya ketika akan menikah. Langkah-langkah adat perkawinan tersebut dimulai dari neundeun omongan, melamar, siraman atau ngebakan, ngeyeuk seureuh, nincak endok, meleum harupat, ngaleupas japati, dan huap lingkung.

\section{Bahasa}

Bahasa mendapat perhatian cukup besar dalam bidang ilmu antropologi karena melalui bahasa lahir suatu kebudayaan. Selain itu, kebudayaan sebagai sistem bahasa (Ratna, 2011). Bahasa sebagai salah satu media yang mewakili gagasan, perasaan, dan pikiran yang terwakili dalam budaya (Hall, 2003). Berikut ini temuan data mengenai bahasa di dalam novel Perempuan Bernama Arjuna karya Remy Sylado.

Yayat Sunarya memotong. "Punten, Arjuna. Jangan salah. Sunda juga punya aksara yang bukan ha-na-ca-ra-ka. Malahan aksara Sunda - sebagaimana dilampirkan contohnya oleh Elis Suryani NS dalam bukunya tentang Kampung Naga ini - ini juga sudah tertata dengan baik, misalnya vokal yang terdiri dari tujuh bunyi yang disebut aksara swara dan konsonan yang terdiri dari duapuluhlima bunyi yang disebutnya aksara ngalegana." (PBA, 2017:184) 


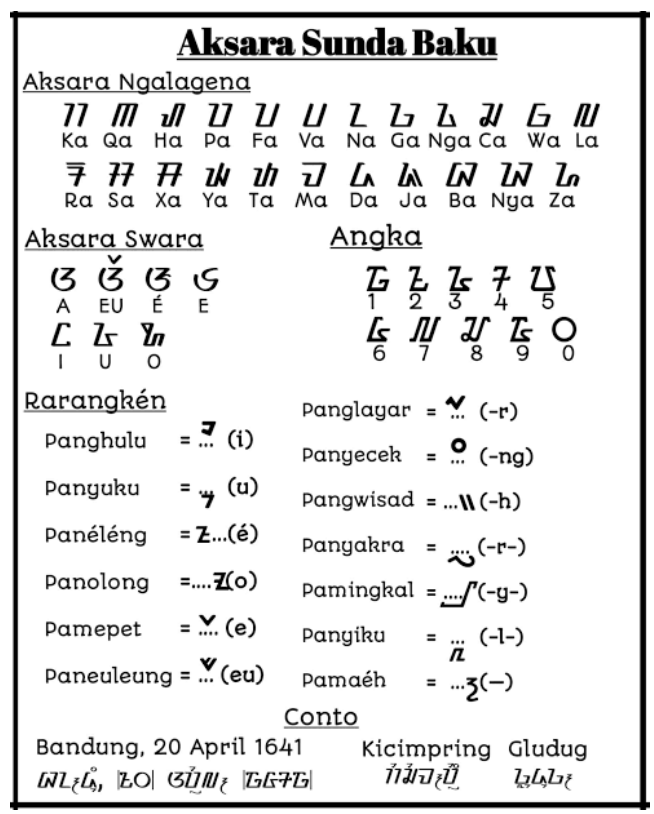

\section{Gambar 1. Aksara Sunda}

Data di atas menunjukan terdapat unsur budaya Sunda berupa bahasa tulisan yang digambarkan melalui aksara Sunda. Aksara Sunda adalah sistem simbol yang tertera pada kertas atau media lainnya untuk mengungkapkan unsur-unsur yang diekspresikan dalam suatu bahasa. Aksara Sunda mendapat pengaruh dari aksara India. Hal ini membuahkan variasi yang berbedabeda dan digunakan untuk menuliskan bahasa daerahnya masing-masing (Definisi ini diambil dari pameran di perpustakaan nasional). Setiap negara memiliki sejumlah aksara daerah untuk menuliskan budayanya (Ratna, 2011). Maka dari itu, peran bahasa dapat mengungkapkan budaya daerah.

\section{SIMPULAN}

Berdasarkan hasil analisis data, disimpulkan budaya Sunda yang terungkap dalam novel Perempuan Bernama Arjuna karya Remy Sylado berbentuk unsur budaya. Adapan unsur budaya Sunda meliputi pertama, sistem pengetahuan sejarah dan kesenian. Pada pengetahuan sejarah diungkapkan mengenai sejarah sunda dan kota/kabupaten di Jawa Barat. Sejarah Sunda menyebutkan bahwa kepulauan di Nusantara ini dahulu kala terdiri dari Sunda besar, kecil, dan laut Sunda. Selain itu, terdapat pengetahuan tentang pelabuhan kerajaan Sunda yakni Sunda Kalapa. Sedangkan, pengetahuan kesenian mengenai angklung, dalam pengetahuan tersebut diungkapkan jenis dan fungsi angklung bagi masyarakat Sunda. Kedua, seni musik. Seni musik menjelaskan tentang alat musik tradisional Sunda yaitu kecapi dan suling. Ketiga, seni tembang. Seni ini lahir dari masyarakat Sunda. Seni tembang ini bercerita tentang kehidupan masyarakat. Keempat organisasi sosial. Bentuk organisai sosial berkenaan dengan perkawinan adar Sunda. Perkawinan adat Sunda ini terdiri dari beberapa langkah di antaranya neundeun omongan, melamar, siraman atau ngebakan dan sebagainya. Kelima bahasa. Jenis bahasa yang dijelaskan yaitu bahasa tulisan. Bahasa tulisan itu berupa aksara Sunda. Kelima unsur budaya tersebut merupakan bagian dari budaya Sunda yang dijelaskan secara rinci melalui novel Perempuan Bernama Arjuna karya Remy Sylado. Diharapkam pemahaman tentang budaya Sunda yang terdapat pada novel Perempuan Bernama Arjuna karya Remy Sylado dapat dijadikan sebagai materi ajar sastra di sekolah. 


\section{DAFTAR PUSTAKA}

Annisa, A. I., \& Indiatmoko, B. (2017). Representasi Sistem Pernikahan Budaya Yogya dalam Novel Perempuan Jogja Karya Achmad Munif. Seloka: Jurnal Pendidikan Bahasa Dan Sastra Indonesia, 6(1), 74-84.

Arini, S. H. D., \& Supriadi, D. (2011). Kacapi Suling Instrumentalia sebagai Salah Satu Kesenian Khas Sunda Harmonia: Journal Of Arts Research And Education, 11(1), 1016. doi: 10.15294/harmonia.v11i1.1498

Choerunisa, K., \& Dahliyana, A. (2017). Internalisasi Nilai Kebudayaan Sunda dalam Program Rebo Nyunda di Kota Bandung. SOSIETAS, 6(2), 1-9.

Emzir. (2016). Metodologi Penelitian Kualitatif Analisis Data. Depok: Rajawali Press.

Endraswara, S. (2013). Metodologi Penelitian Antropologi Sastra: Penerbit Ombak.

Fitriyani, A., Suryadi, K., \& Syam, S. (2015). Peran Keluarga dalam Mengembangkan Nilai Budaya Sunda. SOSIETAS, 5(2), 5-13. doi: https://doi.org/10.17509/sosietas.v5i2.1521

Hall, S. (2003). Representation. London: Sage Publications.

Hardiana, Y. (2017). Pembelajaran Sejarah Indonesia Berbasis Peristiwa-Peristiwa Lokal di Tasikmalaya untuk Meningkatkan Kemampuan Berpikir Kritis. Historia: Jurnal Pendidik dan Peneliti Sejarah, 1(1), 41-46.

Harris, M. (1995). Cultural Anthropology (Fourth Edi). United States of America: Harper Collins College Publishers.

Hermawan, D. (2013). Angklung Sunda sebagai Wahana Industri Kreatif dan Pembentukan Karakter Bangsa. Panggung: Jurnal Seni Budaya, 23(2), 171-186. doi: http://dx.doi.org/10.26742/panggung.v23i2.95

Ihromi, T. O. (2017). Pokok-Pokok Antropologi Budaya. Jakarta: Yayasan Obor Indonesia.

Indrawardana, I. (2012). Kearifan Lokal Adat Masyarakat Sunda dalam Hubungan dengan Lingkungan Alam. Komunitas: International Journal of Indonesian Society And Culture, 4(1), 1-8.

Kadiyono, A. L., \& Harding, D. (2017). Pengaruh Nilai Budaya Sunda dalam Upaya Peningkatan Kesejahteraan Psikologis Korban Bencana Tanah Longsor Journal of Psychological Science and Profession, 1(3), 27-36. doi: https://doi.org/10.24198/jpsp.v1i3.15232.

Koentjaraningrat. (2015). Pengantar Ilmu Antropologi. Jakarta: Rineka Cipta.

Maulana, A. (2013). Kurang, Kesadaran Masyarakat Sunda Menjaga Budaya Sunda.

Mulyana, D. (2012). Cultures and Communication. Bandung: Remaja Rosdakarya.

Pradopo, R. D. (2017). Beberapa Teori Sastra, Metode Kritik, dan Penerapannya. Jakarta: Pustaka Pelajar.

Ratna, N. K. (2011). Antropologi Sastra: Peranan Unsur-Unsur Kebudayaan dalam Proses Kreatif. Yogyakarta: Pustaka Pelajar.

Setiadi, E. M., Kama, A. H., \& Effendi, R. (2008). Ilmu Sosial dan Budaya Dasar. Jakarta: Kencana.

Sugeng, P. (2015). Pengantar Antropologi Memahami Realitas Sosial Budaya. Malang: Intrans Publishing.

Susanti, S., \& Koswara, I. (2017). Menyatukan Perbedaan Melalui Seni Budaya Sunda. Mediator: Jurnal Komunikasi, 10(2), 143-155.

Sylado, R. (2017). Perempuan Bernama Arjuna. Bandung: Nuansa Cendekia.

Wanti, K. (2014). Representasi Kebudayaan Masyarakat Suku Lio dalam Novel Ata Mai. Jurnal NOSI, 2(7), 654-667.

Wiradiredja, M. Y. (2012). Peranan RAA Wiranatakusumah V Dalam Penyebaran Tembang Sunda Cianjuran. Panggung, 22(3), 283-292. 